\title{
ANALYSIS OF GAP FORMATION AT TOOTH-COMPOSITE RESIN INTERFACE: EFFECT OF C-FACTOR AND LIGHT- CURING PROTOCOL
}

\author{
Gustavo Oliveira dos SANTOS ${ }^{1}$, Antônio Henrique Monteiro da Fonseca Thomé da SILVA², \\ José Guilherme Antunes GUIMARÃES ${ }^{3}$, Alexandre de Araújo Lima BARCELLOS ${ }^{3}$, \\ Eduardo Martins SAMPAIO ${ }^{4}$, Eduardo Moreira da SILVA ${ }^{3}$
}

1- MSc, Department of Restorative Dentistry, School of Dentistry, Federal Fluminense University, Niterói, RJ, Brazil.

2- MSc, Department of Mechanical Engineering, School of Engineering, State University of Rio de Janeiro, Nova Friburgo, RJ, Brazil.

3- PhD, Associate Professor, Department of Restorative Dentistry, School of Dentistry, Federal Fluminense University, Niterói, RJ, Brazil.

4- PhD, Associate Professor, Department of Mechanical Engineering, School of Engineering, State University of Rio de Janeiro, Nova Friburgo, RJ, Brazil.

Corresponding address: Dr. Eduardo Moreira da Silva - Universidade Federal Fluminense, Faculdade de Odontologia - Rua Presidente Pedreira, no 97 / 904, 24210-470, - Ingá, Niterói, RJ, Brasil - Phone: 5521 2629-9832 - Fax: 5521 2622-5739 - e-mail: emsilva@vm.uff.br

Received: July 21, 2006 - Modification: March 09, 2007 - Accepted: May 25, 2007

\begin{abstract}
O

bjective: The aim of this study was to evaluate the effect of $\mathrm{C}$-factor and light-curing protocol on gap formation in composite resin restorations. Material and Methods: Cylindrical cavities with $5.0 \mathrm{~mm}$ diameter and three different depths $(\mathrm{A}=1.0, \mathrm{~B}=2.0$ and $\mathrm{C}=3.0 \mathrm{~mm})$ were prepared on the occlusal surface of 30 human molars and restored in a single increment with P 60. The composite resin was light-cured according to two protocols: standard $-850 \mathrm{~mW} / \mathrm{cm}^{2} / 20 \mathrm{~s}$ and gradual - 100 up to 1000 $\mathrm{mW} / \mathrm{cm}^{2} / 10 \mathrm{~s}+1000 \mathrm{~mW} / \mathrm{cm}^{2} / 10 \mathrm{~s}$. After storage in distilled water $\left(37^{\circ} \mathrm{C} / 7\right.$ days $)$, the restorations were cut into three slices in a buccolingual direction and the gap widths were analyzed using a 3D-scanning system. The data were submitted to ANOVA and Student-Newman-Keuls test $(\alpha=0.05)$. Results: ANOVA detected a significant influence for the $\mathrm{C}$-factor and light-curing protocol as independent factors, and for the double interaction C-factor vs. light-curing protocol. Cavities with higher C-factor presented the highest gap formation. The gradual light-curing protocol led to smaller gap formation at cavity interfaces. Conclusions: The findings of this study suggest that the C-factor played an essential role in gap formation. The gradual lightcuring protocol may allow relaxation of composite resin restoration during polymerization reaction.
\end{abstract}

Uniterms: Composite resins; C-Factor; Light-curing protocol; Gap formation; Polymerization shrinkage.

\section{INTRODUCTION}

The volumetric contraction that accompanies resinbased composite (RBC) polymerization, typically to the order of $1.5-5 \%{ }^{13}$, generates stress at the tooth-restoration interface and may lead to marginal gap formation, marginal discoloration, postoperative sensitivity and secondary caries ${ }^{15}$. These clinical consequences of polymerization shrinkage constitute the main reasons for replacing RBC restorations, and explain why polymerization shrinkage is regarded as the main limitation of current $\mathrm{RBCs}^{22}$.

Factors such as polymerization shrinkage, flexural modulus, flow capacity and adhesion to the cavity walls may influence the stress produced in RBC restorations ${ }^{22}$. Strategies to reduce these factors have been studied ${ }^{13}$. Davidson, et al. ${ }^{7}$ (1984), reported that cavity shape is of great importance in conserving the RBC-dentin bond. The shape is described by the configuration factor ' $\mathrm{C}$-factor', which is defined as the ratio of the bonded to unbonded (free) restoration surfaces ${ }^{10}$. It was observed that in most clinically relevant cavity configurations, the stress relieving flow is not sufficient to preserve adhesion to dentin by dentin-bonding agents. Flow capacity may depend on the physical properties of $\mathrm{RBCs}^{3}$, C-factor and polymerization kinetics ${ }^{4}$.

Clinically, the light-curing protocol and the irradiance provided by the light source can influence the polymerization shrinkage stress developed in the material ${ }^{3}$. Activation with a high irradiance creates a rapid light-curing process, leading to higher shrinkage stress in the composite ${ }^{16,32}$. On the other hand, although activation with low irradiance may reduce the development of leakage at tooth-restorative material interface ${ }^{12,27}$, the degree of conversion and mechanical properties of composites can be affected ${ }^{14,21,26,28,31}$. Some recent studies have shown that the use of gradual polymerization, in which the composite is first submitted to 
a low light irradiance, followed by an increase of light intensity, can promote a decrease in shrinkage stress without interfering in the degree of conversion and mechanical properties of the material ${ }^{1,17,20,21,25}$.

The aim of this study was to investigate the influence of the $\mathrm{C}$-factor and light-curing protocol on gap formation in $\mathrm{RBC}$ restorations, and to test a new adhesive interface assessment methodology. The research hypotheses were: (1) the higher the C-factor, the higher the gap formation and (2) the gradual light-curing protocol would reduce gap formation.

\section{MATERIALS AND METHODS}

A commercially available minifilled hybrid $\mathrm{RBC}$ was tested in this study (P60, 3M/ESPE, St. Paul, MN, USA). The composition of the materials used in the restorative procedures is described in Table 1. All specimens were light cured with a quartz-tungsten-halogen unit (Optilux 501; Kerr, Danbury, CT, USA). Two light-curing protocols were used: standard $(\mathrm{S})-850 \mathrm{~mW} / \mathrm{cm}^{2}$ for $20 \mathrm{~s}\left(17 \mathrm{~J} / \mathrm{cm}^{2}\right)$ and gradual (G) -100 to $1000 \mathrm{~mW} / \mathrm{cm}^{2}$ for $10 \mathrm{~s}+1000 \mathrm{~mW} / \mathrm{cm}^{2}$ for $10 \mathrm{~s}$ $\left(\cong 17 \mathrm{~J} / \mathrm{cm}^{2}\right)$. The radiant exposure was calculated as the product of the curing unit irradiance measured with a radiometer (model 100; Demetron Inc., Danbury, CT, USA) by the irradiation time. For $\mathrm{G}$ protocol, the radiant exposure was obtained by the sum of mean irradiance within the first $10 \mathrm{~s}$ multiplied by $10 \mathrm{~s}$ with $10 \mathrm{~J} / \mathrm{cm}^{2}$, corresponding to the radiant exposure in the last $10 \mathrm{~s}$ of light exposure.

\section{Tooth Selection and Preparation}

The steps to gap analysis are illustrated in Figure 1. Thirty human molars free of cracks and structural defects, stored in a $0.5 \%$ chloramine solution for 15 days and frozen in distilled water for less than 3 months were used in this study. All occlusal surfaces were wet ground in a polishing machine (DPU-10, Struers, Copenhagen, Denmark), with 150 and 600-grit $\mathrm{SiC}$ papers until flat dentin surfaces were obtained. The roots were embedded in polyester resin in PVC cylinders ( 0.5 inch in diameter) with the flat dentin surfaces parallel to the cylinder borders, and the teeth were randomly assigned to three groups $(\mathrm{n}=10)$, according to cavity depth. Cylindrical cavities measuring $5.0 \mathrm{~mm}$ in diameter and with three different depths $(\mathrm{A}=1.0, \mathrm{~B}=2.0$ and $\mathrm{C}=3.0 \mathrm{~mm}$ ) were prepared on the flat dentin surfaces with a diamond bur (\# 4054, KG Sorensen, São Paulo, SP, Brazil) in a high-speed handpiece fixed in a special sample aligning device. Cavity depths were controlled by using a digital caliper (MPI/E-101, Mitutoyo, Tokyo, Japan). The C-factor was obtained using the following equation:

$$
C-\text { factor }=\frac{(2 \pi r h)+\pi r^{2}}{\pi r^{2}}
$$

where $r$ is the cavity radius and $h$ is the cavity depth. Therefore, $\mathrm{C}$-factor for each cavity depth was: $\mathrm{A}=1.8 ; \mathrm{B}=2.6$ and $\mathrm{C}=3.4$.

\section{Restorative Procedure}

The cavities were bonded with Single Bond 2 adhesive system (3M/SPE, St. Paul, MN, USA) following manufacturers' instructions, and the composite resin was inserted in a single increment using a flat-sided instrument (Suprafill \#1, SSWhite, Rio de Janeiro, RJ, Brazil). The composite resin was covered with a polyester strip and light cured, in accordance with the two light-curing protocols

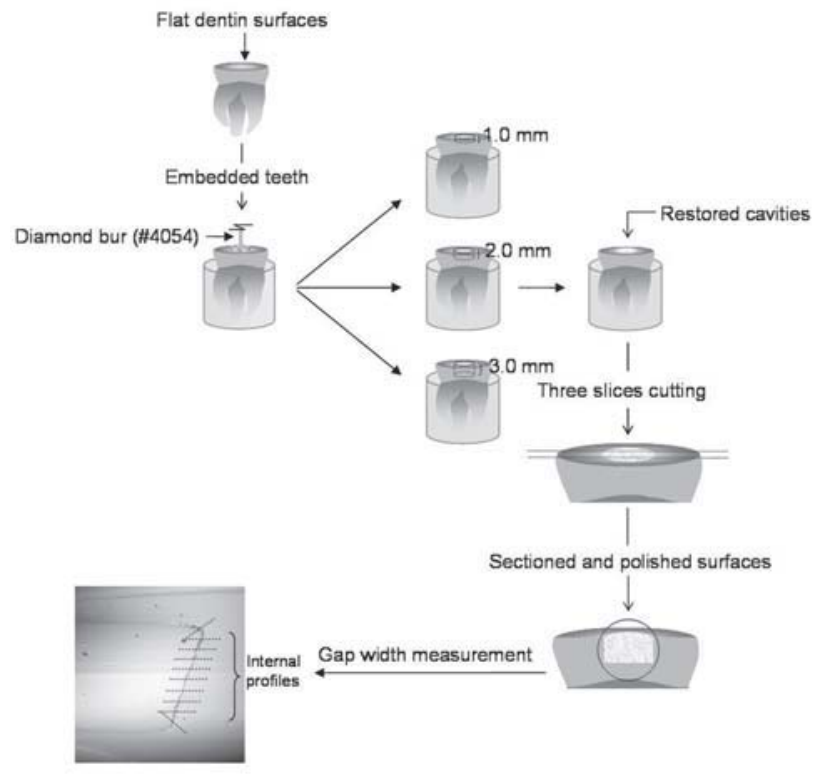

FIGURE 1- Schematic illustration of gap analysis

TABLE 1- Composition of materials used in restorative procedures

Material Manufacturer Composition

Single Bond2 3MESPE

(n 7650;St. Paul, MN, USA)

Filtek P60 (P) 3M ESPE

(n 8490; St. Paul, MN, USA)
BIS-GMA, HEMA, dimethacrylates, ethanol, water, photoinitiator, methacrylate functional copolymer of polyacrylic, polyitaconic acid, polyalkenoic acid, $10 \%$ by weight of 5 nanometer-diameter spherical silica particles

Filler: 61 vol\% silica/zirconia filler with mean particle size of $0.6 \mu \mathrm{m}$ Polymeric matrix: Bis-GMA, Bis-EMA, UDMA TEGDMA 
under study. Six experimental groups were formed according to $\mathrm{C}$-factor and light curing protocol $(\mathrm{n}=5)$. After storage in distilled water at $37^{\circ} \mathrm{C}$ for 7 days, finishing and polishing procedures were performed with sequential Sof Lex discs (3M, St Paul., MN, USA).

The teeth were longitudinally sectioned in a buccolingual direction through the restorations with a diamond disk (KG Sorensen, São Paulo, SP, Brazil) and 3 slices were obtained for each restoration. The sectioned surfaces were polished with 600- and 1200-grit SiC abrasive paper (DPU-10, Struers, Copenhagen, Denmark) and ultrasonicated in distilled water for 5 min (Model 750 USC; Unique, Rio de Janeiro, RJ, Brazil).

\section{Gap Measurement}

Both sides of the polished surfaces were analyzed using a 3D-scanning system (Talyscan 150, Taylor Hobson, Leicester, England) with a space of $1 \mu \mathrm{m}$ in the scanning direction $(x)$ and $60 \mu \mathrm{m}$ in the direction $(y)$ at a scanning speed of $1000 \mu \mathrm{m} / \mathrm{s}$. The images obtained were leveled and roughness profiles of the tooth-restoration surfaces were obtained. Gap width was analyzed at 10 different positions for each slice floor

\section{Statistical Analysis}

Statistical analysis was performed using Statgraphics 5.1 Software (Manugistics, Rockville, MD, USA). Data were analyzed by two-way ANOVA and one-way ANOVA with Student-Newman-Keuls test for multiple comparisons. All statistical analyses were performed at a significance level of $\alpha=0.05$.

\section{RESULTS}

Two-way ANOVA detected a significant influence for the $\mathrm{C}$-factor and light-curing protocol as independent factors $(p<0.0001)$, as well as for the double interaction $C$ factor vs. light-curing protocol $(\mathrm{p}<0.0001)$. The G light-curing protocol yielded the smallest gap formation (Figure 2). Student-Newman-Keuls test showed that the cavities with $\mathrm{C}$-factor $=3.4$ had a higher gap formation than those with $\mathrm{C}$ factors of 2.6 and $1.8(\mathrm{p}<0.0001)$, which did not differ significantly to each other $(p>0.05)$ (Figure 3$)$. Representative photomicrographs of samples are presented in Figure 4.

\section{DISCUSSION}

$\mathrm{RBC}$ polymerization reaction involves the conversion of $\mathrm{C}=\mathrm{C}$ bonds in individual monomer molecules and the formation of $\mathrm{C}-\mathrm{C}$ bonds to form polymer chains, causing volume reduction, as covalent bonds are created and molecular distances and free volume are reduced ${ }^{13}$. The shrinkage generated during this process may cause debonding at tooth cavity-RBC interface, as well as fractures of the enamel prisms along the cavosurface margin, thus leading to clinical failure of the restoration ${ }^{15}$. The polymerization reaction involves three phases: pre-gel, gel and post-gel. In the pre-gel phase, the composite presents a viscous behavior and shrinkage stresses can be released by the material flow relaxation ${ }^{2,6,7,9}$. Polymer chains are distributed in a linear mode and have mobility that permits tensions induced by polymerization shrinkage to be dissipated by flowing. ${ }^{13}$ As the reaction progresses, the post-gel phase starts the first cross links between chains, making flow difficult and simultaneously promoting an increase in mechanical properties and flexural modulus, which involve inducing stresses in the restoration ${ }^{13}$.

Polymerization shrinkage stresses may increase as light intensity generated by the light source increase ${ }^{30}$. Versluis, et al. ${ }^{29}$ (1994), reported that the gel point of RBCs that were light cured with a standard light-curing protocol was reached 1.5-2 $\mathrm{s}$ after the polymerization reaction started. Moreover, a previous study demonstrated that the highest stress development associated with polymerization shrinkage occurs during the first 30 to $40 \mathrm{~s}$ of light irradiation ${ }^{30}$. Based on this, several studies ${ }^{8,11,12}$ have proposed the use of protocols that generated low initial irradiance for light-curing RBCs. A slower curing process can extend the pre-gel phase, allowing relief of polymerization shrinkage stress ${ }^{11,12}$. In the present study, the $\mathrm{G}$ light-curing protocol presented lower gap formation at the tooth-P60 interfaces than $\mathrm{S}$ protocol (Figure 2). This is certainly related to the low initial irradiance ( 100 up to $1000 \mathrm{~mW} / \mathrm{cm}^{2}$ for $10 \mathrm{~s}$ ) provided by $\mathrm{G}$ protocol. In agreement with these findings, Feilzer, et al. ${ }^{12}$ (1995), demonstrated that light curing with low irradiance was related to better marginal sealing of cavities restored with lightcured RBCs. Some previous studies have shown that light curing with low irradiance may decrease the degree of conversion and influence negatively the mechanical

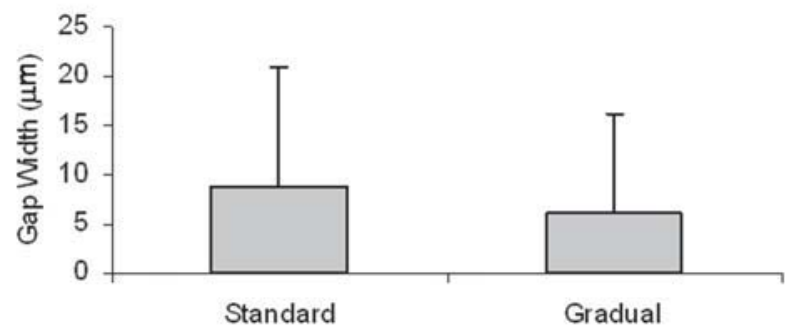

FIGURE 2- Mean gap width $(\mu \mathrm{m})$ for light-curing protocol as an independent factor (vertical bar represents the standard deviation)

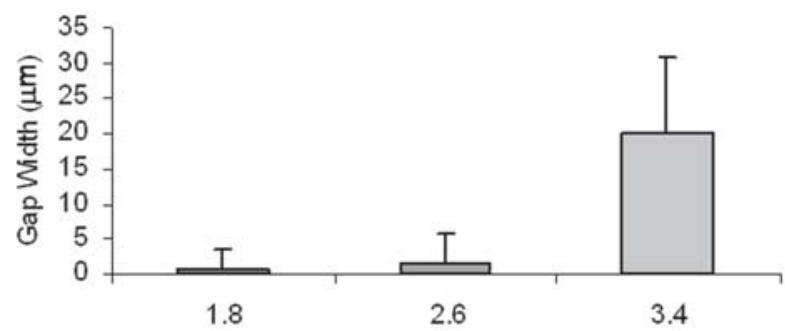

FIGURE 3- Mean gap width $(\mu \mathrm{m})$ for C-factor as an independent factor (vertical bar represents the standard deviation) 
properties of $\mathrm{RBCs}^{24,27,31}$. In spite of the differences in lightcuring protocols, the final radiant exposure used in this study for both techniques was approximately the same $(17 \mathrm{~J} / \mathrm{cm})$. According to Rueggeberg, et al. ${ }^{24}$ (1993), this radiant exposure would be adequate to light cure RBCs. Based on this, it may be assumed that gradual protocols that generate at least $17 \mathrm{~J} / \mathrm{cm}^{2}$ could be indicated for polymerizing RBCs.

The influence of the confinement conditions imposed on the composite resin (usually expressed as the bonded to unbonded ratio, known as $\mathrm{C}$-factor) plays an essential role in gap formation at cavity-composite interfaces. According to Feilzer, et al. ${ }^{10}$ (1987), most clinical restorations have Cfactor values of approximately 1 to 2 . Improvements in adhesive systems and composite resins have, however, encouraged dental practitioners to build deeper restorations that have a high $\mathrm{C}$-factor. As a result, a cavity with $\mathrm{C}$-factor of 3.4 was introduced in the present study, to simulate a more realistic clinical situation. Braga, et al. ${ }^{4}$ (2006), analyzing the influence of cavity dimensions on shrinkage stress and microleakage in composite restorations, showed that cavity depth had a stronger influence on both responses than diameter. Based on this, the cavity diameters in the present
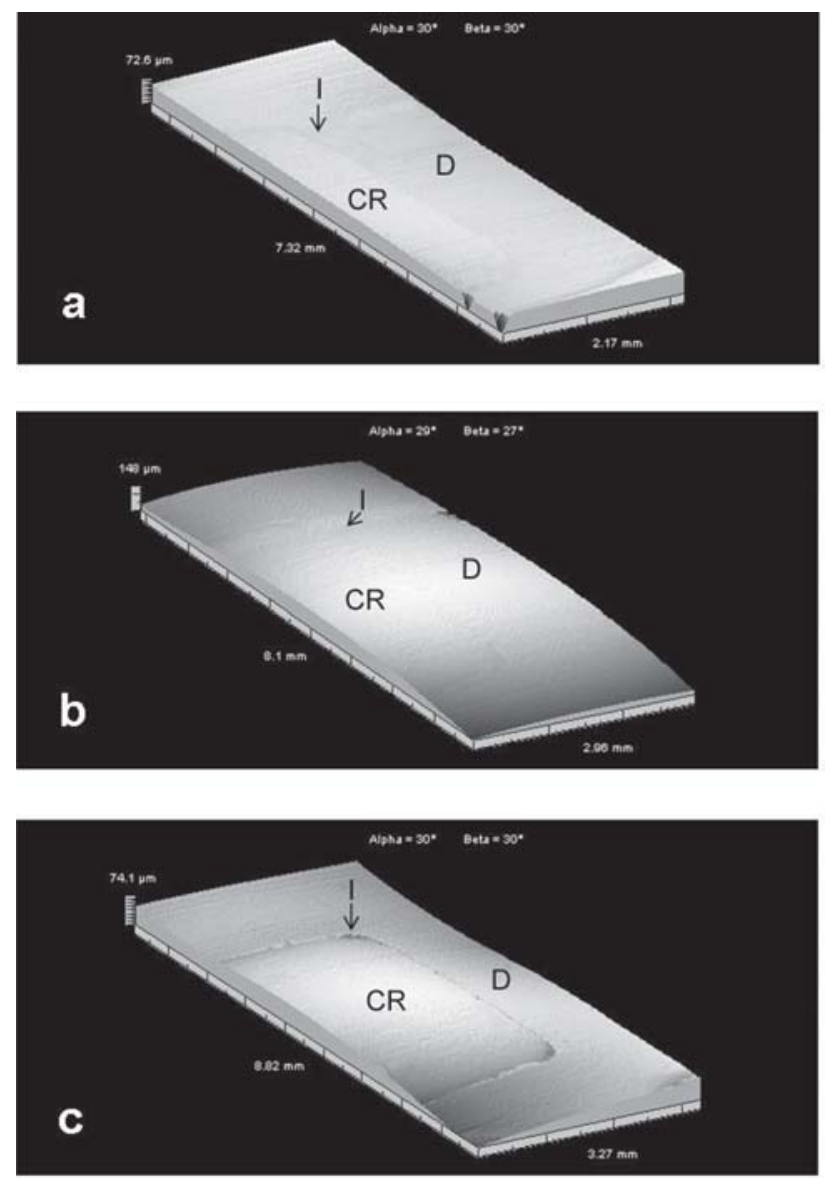

FIGURE 4- Representative photomicrographs of the specimens. In (a) and (b), cavities with $1 \mathrm{~mm}$ depth (Cfactor 1.8 ) and $2 \mathrm{~mm}$ depth (C-factor 2.6), respectively. No gap formation was observed at the tooth-composite resin interfaces. In (c), a cavity with $3 \mathrm{~mm}$ depth (C-factor 3.4 ). Gap formation can be observed along the tooth-composite resin interface. (D) dentin; (CR) composite resin; (I) interface study were kept constant $(5.0 \mathrm{~mm})$ and the C-factor was varied as a function of cavity depths (1.0,2.0 and $3.0 \mathrm{~mm})$.

Gap formation was higher in cavities with $\mathrm{C}$-factor $=3.4$ than in those with 2.6 and $1.8 \mathrm{C}$-factors. Moreover, all cavities with $\mathrm{C}$-factor $=3.4$ presented a gap at the tooth-composite resin interface (Figure 4). On the other hand, in the groups with C-factor 1.8 and 2.6, only slices from one cavity per group showed gap formation at the tooth-composite resin interface. From the clinical point of view, this finding is extremely important because the absence of gap would increase the longevity of composite resin restorations. Interpretation of these results may be based on the fact that in cavities with $\mathrm{C}$-factor 1.8 and 2.6, the composite relaxation provided by the unbonded surface, which was the same for both cavities, was more efficient for relieving shrinkage stress generated during the polymerization reaction ${ }^{10,18}$. On the other hand, the greater depth of the cavities with $\mathrm{C}$-factor 3.4 increased the bonded interface. Thus, the wall-to-wall shrinkage was increased and so was the gap formation. These results agree with previous studies. Yoshikawa, et al. ${ }^{32}$ (2001), found that cavity-wall gap formation significantly increased when the C-factor increased from 2.3 to 3 , and concluded that a $\mathrm{C}$-factor of 2.3 can be considered low. Furthermore, Loguercio, et al. ${ }^{19}$ (2004), showed that the linear polymerization shrinkage and the gap width were higher when the C-factor increased from 0.3 to 3.0. An important aspect was that these authors measured the linear polymerization shrinkage of the composite resin inside the restored cavities. In addition, some previous studies have shown that the increase in the $\mathrm{C}$-factor also has a harmful effect on the bond strength of adhesive systems to $\operatorname{dentin}^{19,23}$.

Figure 4 shows representative photomicrographs of specimens. In (c), great gap formation at the internal angles in a 3-mm-deep cavity can be seen. This feature was observed in all specimens that presented gap formation at the toothP60 interface. This finding could be explained by the high shrinkage stress concentration generated by the wall-towall bonding competition in these areas, i.e. floor vs. axial wall cavity ${ }^{4}$. On the other hand, it can be seen that in the cavosurface region the sealing was more satisfactory. Probably, the relaxation of P60 free surface could have allowed more stress relief in these areas, allowing the adhesive system to support the debonding phenomenon ${ }^{6}$. These findings explain why in the present study the gap measurement was analyzed only on the cavity floor.

Based on the obtained results, it may be assumed that gap formation is a multifactorial phenomenon, dependent on several factors ${ }^{22}$ related to the restorative material, $\mathrm{C}$ factor $^{4,6,10,32}$ and light-curing protocol ${ }^{12,20,25-28}$. Furthermore, it is also important to study other factors, such as composite resin incremental technique and the use of lining materials ${ }^{13}$ in order to improve restoration sealing. Further studies should be conducted in order to yield better sealing of cavities restored with light-cured RBCs. 


\section{CONCLUSIONS}

The results of this in vitro study supported the research hypotheses. It may be concluded that: 1. High C-factor values produced the highest gap formation; 2 . The gradual light-curing protocol was effective in reducing gap formation.

\section{ACKNOWLEDGEMENTS}

This study was supported by the Adhesion and Adherence Laboratory (LAA), from the Department of Mechanical Engineering of the State University of Rio de Janeiro, Brazil. The authors would like to thank 3M/ESPE for supplying the materials used in this study.

\section{REFERENCES}

1- Barros GK, Aguiar FH, Santos AJ, Lovadino JR. Effect of different intensity light curing modes on microleakage of two resin composite restorations. Oper Dent. 2003;28:642-6.

2- Bausch JR, de Lange K, Davidson CL, Peters A, de Gee AJ. Clinical significance of polymerization shrinkage of composite resins. J Prosthet Dent. 1982;48:59-67.

3- Bouschlicher MR, Rueggeberg FA, Boyer DB. Effect of stepped light intensity on polymerization force and conversion in a photoactivated composite. J Esthet Dent. 2000;12:23-32.

4- Braga RR, Boaro LC, Kuroe T, Azevedo CL, Singer JM. Influence of cavity dimensions and their derivatives (volume and ' $\mathrm{C}$ ' factor) on shrinkage stress development and microleakage of composite restorations. Dent Mater. 2006;22:818-23

5- Carvalho RM, Pereira JC, Yoshiyama M, Pashley DH. A review of polymerization contraction: the influence of stress development versus stress relief. Oper Dent. 1996;21:17-24.

6- Davidson CL, de Gee AJ. Relaxation of polymerization contraction stresses by flow in dental composites. J Dent Res. 1984;63:146-8.

7- Davidson CL, de Gee AJ, Feilzer A. The competition between the composite-dentin bond strength and the polymerization contraction stress. J Dent Res. 1984;63:1396-9.

8- Davidson CL, Feilzer AJ. Polymerization shrinkage and polymerization shrinkage stress in polymer-based restoratives. J Dent. $1997 ; 25: 435-40$

9- Emami N, Soderholm KJ, Berglund LA. Effect of light power density variations on bulk curing properties of dental composites. J Dent. 2003;31:189-96.

10 - Feilzer AJ, de Gee AJ, Davidson CL. Setting stress in composite resin in relation to configuration of the restoration. J Dent Res. 1987;66:16369.

11 - Feilzer AJ, de Gee AJ, Davidson CL. Setting stresses in composites for two different curing modes. Dent Mater. 1993;9:2-5.

12 - Feilzer AJ, Dooren LH, de Gee AJ, Davidson CL. Influence of light intensity on polymerization shrinkage and integrity of the restorationcavity interface. Eur J Oral Sci. 1995;103:322-6.
13 - Ferracane JL. Developing a more complete understanding of stresses produced in dental composites during polymerization. Dent Mater. $2005 ; 21: 36-42$

14- Halvorson RH, Erickson RL, Davidson CL. Energy dependent polymerization of resin-based composite. Dent Mater. 2002;18:463-9.

15- Hickel R, Manhart J. Longevity of restorations in posterior teeth and reasons for failure. J Adhes Dent. 2001;3:45-64.

16- Jain P, Pershing A. Depth of cure and microleakage with highintensity and ramped resin-based composite curing lights. J Am Dent Assoc. 2003;134:1215-23

17- Koran P, Kurschner R. Effect of sequential versus continuous irradiation of a light-cured resin composite on shrinkage, viscosity, adhesion and degree of polymerization. Am J Dent. 1998;11:17-22.

18- Li Y, Swartz ML, Phillips RW, Moore BK, Roberts TA. Effect of filler content and size on properties of composites. J Dent Res. 1985;64:1396-401.

19- Loguercio AD, Reis A, Ballester RY. Polymerization shrinkage: effects of constraint and filling technique in composite restorations. Dent Mater. 2004;20:236-43.

20- Mehl A, Hickel R, Kunzelmann KH. Physical properties and gap formation of light-cured composites with and without 'softstartpolymerization'. J Dent. 1997;25:321-30.

21 - Muangmingsuk A, Senawongse P, Yudhasaraprasithi S. Influence of different softstart polymerization techniques on marginal adaptation of Class V restorations. Am J Dent. 2003;16:117-9.

22 - Peutzfeldt A, Asmussen E. Determinants of in vitro gap formation of resin composites. J Dent. 2004;32:109-15.

23 - Price RB, Dérand T, Andreou P, Murphy D. The effect of two configuration factors, time, and thermal cycling on resin to dentin bond strengths Biomaterials. 2003;24:1013-21.

24- Rueggeberg FA, Caughman WF, Curtis JW Jr, Davis HC. Factors affecting cure at depths within light-activated resin composites. Am J Dent. 1993;6:91-5

25- Sakaguchi RL, Berge HX. Reduced light energy density decreases post-gel contraction while maintaining degree of conversion in composites. J Dent. 1998;26:695-700.

26- Uno S, Asmussen E. Marginal adaptation of a restorative resin polymerized at a reduced rate. Scand J Dent Res. 1991;99:440-4.

27- Unterbrink GL, Muessner R. Influence of light intensity on two restorative systems. J Dent. 1995;23:183-9.

28- Vandewalle KS, Ferracane JL, Hilton TJ, Erickson RL, Sakaguchi RL. Effect of energy density on properties and marginal integrity of posterior resin composite restorations. Dent Mater. 2004;20:96-106.

29- Verluis A, Sakagushi RL, Douglas WH. Stress development in composite resins during polymerization [abstract 1000]. J Dent Res. $1994 ; 73: 226$

30- Watts DC, Cash AJ. Determination of polymerization shrinkage kinetics in visible-light-cured materials: methods development. Dent Mater. 1991;7:281-7.

31- Yap AU, Seneviratne C. Influence of light energy density on effectiveness of composite cure. Oper Dent. 2001;26:460-6.

32 - Yoshikawa T, Burrow M.F, Tagami J. The effects of bonding system and light curing method on reducing stress of different $\mathrm{C}$-factor cavities. J Adhes Dent. 2001;17:177-83. 